\title{
Towards an automatic lidar cirrus cloud retrieval for climate studies
}

\author{
E. G. Larroza ${ }^{1}$, W. M. Nakaema ${ }^{1}$, R. Bourayou ${ }^{1}$, C. Hoareau ${ }^{2}$, E. Landulfo ${ }^{1}$, and P. Keckhut ${ }^{3}$ \\ ${ }^{1}$ CLA, IPEN/CNEN-SP, Center for Lasers and Applications, Av. Prof. Lineu Prestes, 2242 São Paulo, SP 05508-000, Brazil \\ ${ }^{2}$ LMD-IPSL, École Polytechnique, Route de Saclay, 91128 Palaiseau Cedex, France \\ ${ }^{3}$ LATMOS-IPSL, Univesité de Versaille Saint-Quentin (bureau 1323) 11, boulevard d'Alembert, 78280 Guyancourt, France \\ Correspondence to: E. G. Larroza (elarroza.ipen@gmail.com) and P. Keckhut (keckhut@latmos.ipsl.fr)
}

Received: 26 March 2013 - Published in Atmos. Meas. Tech. Discuss.: 30 April 2013

Revised: 14 October 2013 - Accepted: 16 October 2013 - Published: 26 November 2013

\begin{abstract}
This paper presents a methodology to calculate lidar ratios for distinct cirrus clouds that has been developed and implemented for a site located in the Southern Hemisphere. The cirrus cloud lidar data processing aims to consider a large cloud variability and cirrus cloud monitoring through a robust retrieval process. Among cirrus features estimates for complex scenes that lidar systems can provide, we highlight cloud geometrical information and extinctionto-backscatter ratio (known as lidar ratio or LR). In general, direct information on cirrus cloud microphysics is difficult to derive because LR depends on the presence of ice crystals and their properties such as shape, size, composition and orientation of particles. An iterative process to derive a stable LR value has been proposed. One of the keys is to restrict the analysis to conditions allowing accurate multilayer events. This method uses nonparametric statistical approaches to identify stationary periods according to cloud features and variability. Measurements performed in the region of the metropolitan city of São Paulo (MSP) have been used to implement and test the methodology developed for cirrus cloud characterization. Good results are represented by examining specific cases with multilayer cirrus cloud occurrence. In addition to the geometrical parameters obtained, cirrus LR values were calculated for a single day ranging from $19 \pm 01 \mathrm{sr}$ to $74 \pm 13 \mathrm{sr}$ for 2 observed layers. This large difference in LR can indicate a mixture of ice crystal particles with different sizes and shapes in both layers of the cirrus clouds. Trajectory analyses indicate that both of these cloud layers can be associated with different air mass and should be considered as 2 distinct clouds in climatology.
\end{abstract}

\section{Introduction}

The assessment of the impact of cirrus clouds in climate is complex (Liou, 1986) due to their influence on both Earth's incoming and its outgoing solar radiation, with their variable radiative and optical properties affecting both the cooling and heating of Earth's atmosphere (Ramanathan and Collins, 1991). Even their topology in the atmosphere shows an interesting pattern, which has a direct impact in the presence of ice crystals of different shapes and sizes (Takano and Liou, 1995) and in the presence of liquid water at temperatures well below freezing (Hallett et al., 2002). Their abundance in the atmosphere at any time can span (on average) from $30 \%$ over the entire globe up to $70 \%$ over the Tropics (Wang et al., 1996; Nazaryan et al., 2008; Dupont et al., 2010). Additionally, cirrus cloud observation has become much more elusive since a considerable fraction of the clouds are relatively optically thin (in the visible spectrum; Sassen et al., 2008).

Facing this large diversity of characteristics that, currently, are virtually impossible to measure with a single instrument, one can expect that clouds formed in similar conditions and involving similar physical processes exhibit similar crystal characteristics. Cirrus cloud occurrence, their effects on climate, and their simulation by numerical models are known to be different, depending on their causes of formation. Advances in modeling capability to predict climate change require improved representations of cloud processes in models, as well as a reduction of uncertainties in parameterizations of cloud-radiation interaction (Nazaryan et al., 2008). For these reasons, it is important to identify different classes of cirrus clouds based on the processes involved. Sassen and Cho (1992) proposed a threshold of 0.03 for their optical depth to discriminate cirrus clouds into visible and subvisual 
clouds. Besides optical depth as a critical parameter to describe clouds, many other features, such as crystal shape, size, distribution, composition, etc., are important for radiative issues. Cirrus cloud characteristics, such as their composition, particle density, size and shape, vary with altitude and depend on formation processes (Dupont et al., 2010). Knowledge about the cloud particle density distribution with altitude is essential for understanding the radiative balance between the greenhouse effect (terrestrial infrared energy) and albedo (solar visible radiation). Cirrus cloud formation is associated with upwelling motions, either due to frontogenesis or convection. It is also strongly driven by horizontal water vapor transport over a wide range of scales (local to continental), including isentropic advection (Fueglistaler et al., 2004; Keckhut et al., 2005; Montoux et al., 2010) and phase changes. Also, cyclones and airplane contrails provide conditions for cirrus cloud generation, presenting particular unique characteristics. These processes lead to significant vertical and temporal heterogeneities that may also have a strong impact on the radiative balance. Therefore, the parameterization of high clouds in climate models needs to properly assess the temporal and spatial distribution of their properties (Ringer and Allan, 2004; Li et al., 2005; Nazaryan et al., 2008).

In spite of satellite data covering large areas of the globe, measurements from space-borne platforms still exhibit some limitations for cirrus clouds studies. Such clouds can present multilayered formations or be optically thin, leading to ambiguities or significant uncertainties. Although measurements from CloudSat and CALIPSO (Cloud Sat/Cloud-aerosol Lidar and Infrared Pathfinder Satellite Observations), which support a cloud radar and polarization lidar, respectively, are able to identify and accurately measure this cloud category (Sassen et al., 2008), they do not completely satisfy the need to track the cirrus coverage over the entire globe.

Due to a limited number of vertical and temporal highresolution measurements of cloud microphysical properties, especially in the tropical/subtropical region of South America, an accurate determination of the radiative forcing of cirrus clouds is difficult to assess. Measurements in this sense can only be achieved with radar and lidar systems (Seifert et al., 2007). However, cirrus clouds characterization is problematic since such clouds are ubiquitous (Liou, 1986) and their bulk microphysical properties are highly variable (Heymsfield, 1972). The uncertainties associated with this variability can be transferred to the time-series measurements of backscattering coefficients derived from lidar signals. Nonetheless, ground-based lidar observations provide useful information linking macrophysical, optical, and microphysical properties of cirrus clouds with synoptic and radiative processes (Sassen and Campbell, 2001; Sassen and Benson, 2001; Sassen and Comstock, 2001; Sassen et al., 2003, 2007). Some investigations about the vertical distribution of cirrus clouds have revealed an identification of clusters that can be associated with specific formation processes (Keckhut et al., 2006; Hoareau et al., 2012).
In this sense, single wavelength lidar can provide an important parameter called the extinction to backscattering ratio, i.e., lidar ratio (LR). LR depends on several characteristics of the particles, including their shape, size distribution and refractive index (Ansmann et al., 1992; Ackermann, 1998; Ansmann, 2002; Chen et al., 2002; Barnaba and Gobbi, 2004; Cadet et al., 2005; Josset et al., 2012). Therefore, LR can provide indications about the ice-crystal characteristics (Sassen et al., 1989; Ansmann, 2002; Petty et al., 2006). In addition, such a parameter is required to retrieve an accurate backscattering ratio through the determination of the extinction coefficient $\alpha(z)$ from the signal retrievals (Petty et al., 2006). Accurate estimates depend on many factors such as optical depth $\left(\tau_{\text {cir }}<0.03\right.$ for subvisible clouds; Sassen and Cho, 1992; Sassen et al., 2008), variable multiscattering effects inside cloud layers, and lidar signals that are mainly driven by the statistical noise level.

However, one important limitation of single wavelength lidar is the difficulty in the determination of extinction and backscattering coefficients. The most common procedure used to obtain the extinction coefficient of cirrus cloud is the Klett inversion lidar method (Klett, 1985). The most critical input parameter in the Klett method is the value of cirrus LR, which can vary over more than two orders of magnitude within a few meters. From the signal attenuation, one can derived the LR (Chen et al., 2002). However, depending on the signal quality and cloud optical depth amplitude, this parameter can be obtained with reasonable accuracy (typically 10$20 \%$ ) or with worthless large uncertainty in the case of both of thin or thick clouds (Cadet et al., 2005). Here a methodology is proposed to derive the LR parameter when the conditions are favorable for including multilayer events. LR of cirrus clouds are derived using an iterative process and without assuming any constant values for this parameter.

Also, in order to obtain a reliable statistical data set of vertical distribution characteristics and optical properties for different categories of cirrus clouds, a large number of photons need to be collected and then lidar signals averaged. In addition, due to the high spatiotemporal geophysical variability, the selected periods need to include consistent cloud information and careful investigations are required to select cloud sceneries. Then, to provide pertinent and more robust information about cloud altitude, thickness and optical depth $\left(\tau_{\text {cir }}\right)$, a nonparametric statistical method (Lanzante, 1996) is used. It defines a so-called stationary period when clouds could exhibit similar micro- and macrophysical properties and molecular scattering can be detected above clouds to perform accurate retrievals. Multilayered cirrus clouds are also an issue when cloud thickness or optical depths are derived. In these cases, it is a challenge to derive their individual optical properties if layers exhibit overlap and then no pure Rayleigh scattering between layers can be observed. Selected lidar data are used when it is feasible to provide improved cloud characteristic retrieval, which will help to obtain consistent cirrus cloud families according 


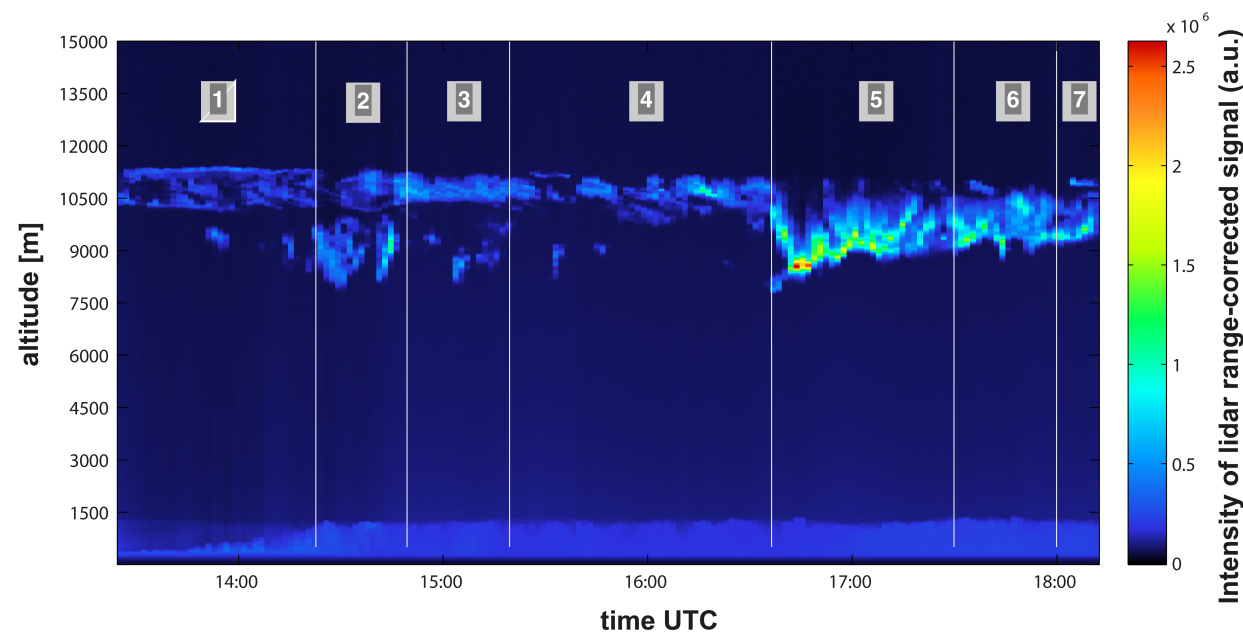

Fig. 1. A typical lidar range corrected signal display of the troposphere for 11 June 2007, when cirrus clouds were observed by the MPS-lidar $\left(23^{\circ} 33^{\prime} \mathrm{S}, 46^{\circ} 44^{\prime} \mathrm{W}\right)$ over São Paulo City, Brazil. Note the aerosol backscattering layer up to $1 \mathrm{~km}$, while the cirrus clouds are detected between 8.0 and $11.5 \mathrm{~km}$. The stationary periods are represented by seven observational periods (also shown in Figs. 4 and 5 ) delimited by white vertical lines.

to their formation. These databases will be useful to investigate cases where those processes are properly included in numerical models, leading to a proper climate radiation budget (Josset et al., 2012). Lidar measurements performed in the São Paulo region provide a good opportunity to understand cirrus morphology and their effects on a regional basis. While the methodology is based on these lidar data sets, the methodology and criteria are universal and can be applied to any lidar data.

The manuscript is organized as follows: Sect. 2 presents a brief description of the lidar system used; in Sect. 3 the methodology is described, providing the full cirrus cloud macrophysical and optical properties derived from these lidar observations for a case study when cirrus clouds were detected (11 June 2007). Data selection criteria and multiple scattering effects corrections of the derived optical properties $\tau_{\text {cir }}$ and LR are included. The overall uncertainties in the exposed methodology are discussed in Sect. 4; results are discussed in Sect. 5 and the main conclusions are in Sect. 6.

\section{Description of the lidar and location}

A ground-based elastic backscatter lidar, located in the metropolitan city of São Paulo $\left(23^{\circ} 33^{\prime} \mathrm{S}, 46^{\circ} 44^{\prime} \mathrm{W}\right)$ in Brazil, has been operated in the Laboratory of Environmental Laser Applications at the Center for Lasers and Applications (CLA) at the Instituto de Pesquisas Energéticas e Nucleares (IPEN) since 2001 (Landulfo et al., 2003). This system was initially implemented for measurements of aerosols and the atmospheric boundary layers estimation, while the systematic cirrus cloud measurements started in 2004 and remain ongoing.
The lidar is a single-wavelength backscatter system pointing vertically to the zenith and operating in the coaxial mode. The light source is based on a commercial Nd:YAG laser (Brilliant by Quantel SA) operating at the second harmonic frequency (SHF), nominally at $532 \mathrm{~nm}$ for cirrus detection, with a fixed repetition rate of $20 \mathrm{~Hz}$. The average emitted power can be selected up to values as high as $3.3 \mathrm{~W}$. The emitted laser pulses have a divergence smaller than $0.5 \mathrm{mrad}$. A $30 \mathrm{~cm}$ diameter telescope (focal length $f=1.3 \mathrm{~m}$ ) is used to collect the backscattered laser light. The temporal resolution of measurements is $\sim 2 \mathrm{~min}$ and the vertical resolution is $15 \mathrm{~m}$. The data acquisition was mostly performed in dualmode, i.e. both analog and photon counting. The photoncounting mode was first employed to define a threshold factor to accurately define the base and top of the cirrus clouds. This threshold factor (Eq. 3) depends on the uncertainty of the attenuated scattering ratio (see definition below), but especially beyond the cloud top the analog signal is quite worthless due to the noise (Fig. 4b). Therefore, the photon-counting signals were used to derive attenuation and cloud scattering and the noise uncertainty (Eq. 4), which is dominated by photon counting.

The studied region presents a humid subtropical climate. During winter (when the measurements were carried out), the temperatures usually ranged between $11^{\circ} \mathrm{C}$ and $23^{\circ} \mathrm{C}$. The average precipitation registered in this period was about $47 \mathrm{~mm}$, representing a dry season for the southeast region in Brazil. The weather predominantly consisted of relatively cool and clean sky days, with eventual frontal system passages. Moreover, inversion events were most frequent during this period, resulting in trapped pollution close to the ground in such a way that the boundary layer did not exceed $1.5 \mathrm{~km}$ 
(Fig. 1). For these reasons, most of the lidar measurements were carried out during the wintertime.

\section{Methods}

This section describes the methodology applied in this work, from the selection of cirrus events, treatment of the signal, statistical analyses and final determination of cirrus optical parameters. In order to obtain a reasonable compromise between measurement accuracy and atmospheric variability, the time series of the optical depth and cloud thickness are analyzed through the Lanzante method (Lanzante, 1996). This method is designed to find discontinuity points and determine periods of quasi-stationary conditions with respect to statistical variability. Data analyses are then performed on these integrated periods to derive accurate optical cirrus properties (LR and the $\tau_{\text {cir }}$ ) and their macrophysical parameters (base and top of cloud, their respectively temperatures and thickness). Initially, an attenuated or apparent scattering ratio profile $\left(\mathrm{SR}_{\mathrm{app}}\right.$ as defined in Eq. 1) is calculated. The transmittance method (Chen et al., 2002) is used to obtain the $\tau_{\text {cir. }}$. Both parameters are then used to determine the LR according to the relation described in Goldfarb et al. (2001). Especially this last parameter is determined by an iterative process (as described in Sect. 3.2.1) until a "stable" value is obtained. Simultaneously, the apparent SR profile is corrected during this iterative process, producing a new corrected SR profile $\left(\mathrm{SR}_{\text {corr,norm }}\right)$.

\subsection{Signal analysis, selection of the cirrus clouds and determination of stationary periods}

In order to illustrate the methodology used in the current study, a case study of lidar measurements performed at São Paulo on 11 July 2007 is examined. Figure 1 illustrates a typical lidar range corrected signal of the troposphere for the specified date. Cirrus clouds were observed by the MPS-lidar $\left(23^{\circ} 33^{\prime} \mathrm{S}, 46^{\circ} 44^{\prime} \mathrm{W}\right)$ over São Paulo City, Brazil. One can see the aerosol backscattering layer up to $1 \mathrm{~km}$, while the cirrus clouds are detected between 8.0 and $11.5 \mathrm{~km}$. The stationary periods are represented by seven observational periods (also shown in Figs. 4 and 5) separated by white vertical lines.

The origin of the detected cirrus can be associated with several phenomena such as deep-convection cumulus clouds and air mass injection provided from the inter-tropical convergence zone (ITCZ) several days before their detection.

In order to determine the origin of these air masses detected by the lidar, $72 \mathrm{~h}$ backward trajectories were generated using the HYSPLIT model (Draxler and Rolph, 2013). Figure 2 shows two backward trajectories ending at 15:00 UTC on 11 June 2007, corresponding to two altitudes, $9 \mathrm{~km}$ and $11 \mathrm{~km}$, where two separated cirrus layers are observed (see Fig. 1 time interval denoted by 15:00 UTC). These trajecto-

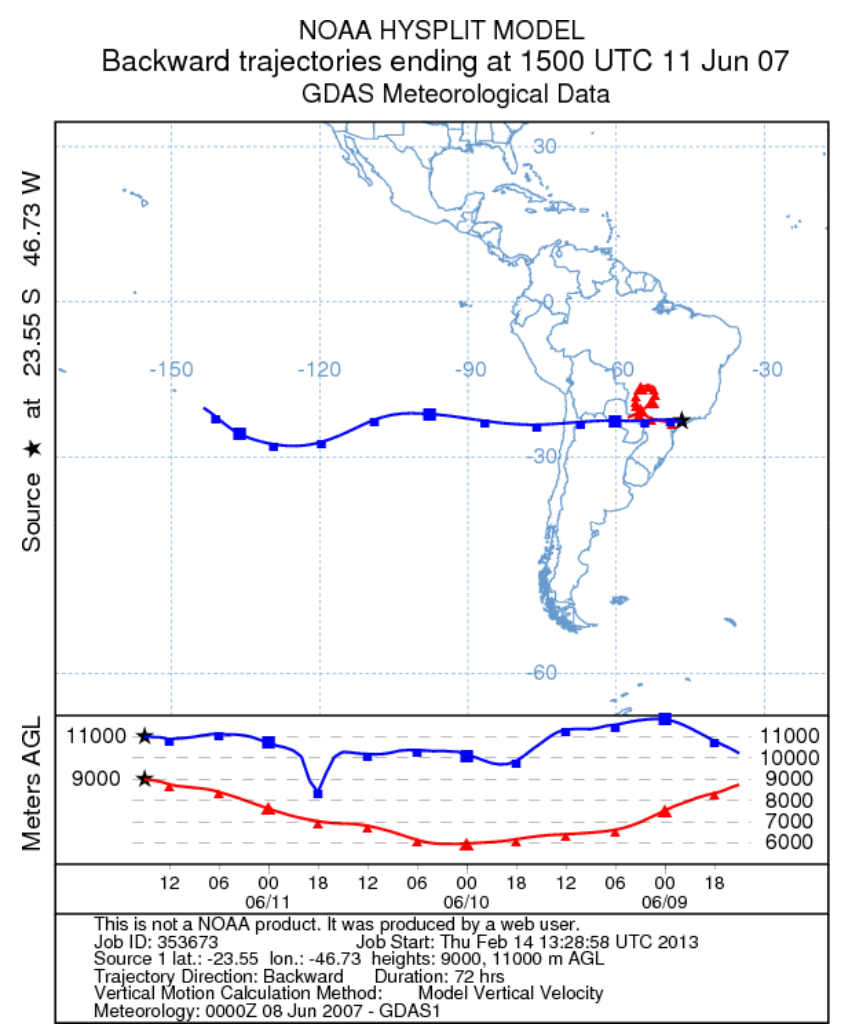

Fig. 2. NOAA HYSPLIT model backward trajectories ending at 15:00 UTC on 11 June 2007 corresponding to the city of São Paulo $\left(23^{\circ} 33^{\prime} \mathrm{S}, 46^{\circ} 44^{\prime} \mathrm{W}\right)$ showing the origin of air masses for the respective altitudes $(\sim 9 \mathrm{~km}$ and $11 \mathrm{~km})$ where cirrus clouds were detected by the MSP-lidar. The sequence of ending time was chosen on purpose to coincide with the period when two distinct cirrus layers were observed in Fig. 1, indicating here different origins.

ries are quite stable over several hours, revealing that both layers indeed correspond to two cirrus clouds from different origins. Consequently, cirrus cloud climatology should take into account multilayer cases which are not always due to a vertical structure of the same cloud. It could correspond to different air masses arriving at different altitudes, potentially presenting different optical properties. In particular, the layer of clouds observed between 14:00 and 16:00 UTC at approximately $9 \mathrm{~km}$ (Fig. 1) corresponds to air masses with origin mostly from the central western part of Brazil (see Fig. 2, red line), and the layer detected around $11 \mathrm{~km}$ (see Fig. 2, blue line) corresponds to air masses coming from the South Pacific Ocean.

The ratio between the range-corrected and backgroundsubtracted signal $X(z)$ at a range $z$ and the total backscattering coefficient $X\left(z_{m}\right)$ at a reference range $z_{m}$ corresponding to an aerosol-free range defines the attenuated or apparent scattering ratio $\left(\mathrm{SR}_{\mathrm{app}}\right)$ :

$\mathrm{SR}_{\mathrm{app}}=\frac{X(z)}{X\left(z_{m}\right)}=\frac{\left(\beta_{\text {Rayleigh }}(z)+\beta_{\text {Mie }}(z)\right)}{\beta_{\text {Rayleigh }}\left(z_{m}\right)} e^{-2 \int_{z}^{z m} \alpha\left(z^{\prime}\right) d z^{\prime}}$, 
where the term $\alpha(z)$ is the total extinction coefficient neglecting the absorption by gases.

The signal consists of an individual lidar measurement obtained during a time-average of the return signals, typically over two minutes. The molecular backscattering $\beta_{\text {Rayleigh }}\left(z_{m}\right)$ can be estimated from a dry air density profile, retrieved from the conventional radiosonde observation profile (Bucholtz, 1995). Only lidar profiles containing a cirrus cloud signature were retained. To clearly differentiate a cirrus cloud from a water cloud we considered two conditions, a limit for the cloud base height and its correspondent temperature. For example, Das et al. (2009) considered lidar signals only above $8 \mathrm{~km}$. In our case those signals displaying a cloud base below $7.5 \mathrm{~km}$ were discarded. Clouds presenting base temperature (derived from radiosonde observations) above $-20^{\circ} \mathrm{C}$ were also avoided. Below this temperature, clouds particles present polycrystalline patterns that can be used to differentiate between ice clouds and water clouds (Heymsfield and Platt, 1984).

In an atmosphere free of aerosols, the scattering ratio should be a unity by definition. However, Eq. (1) defines the $\mathrm{SR}_{\mathrm{app}}$ as the ratio of experimental and modeled quantities; the denominator is as mentioned before, calculated from the profiles of thermodynamic quantities measured by radiosondes, or simply approximated using an exponential fit of the lidar-measured profile in an altitude range where a free atmosphere is assumed. For these reasons, $\mathrm{SR}_{\text {app }}$ might deviate from unity. Our period-averaged $\mathrm{SR}_{\text {app }}$ profiles are normalized by a factor $k$ in order to assess a mean value of unity in the typical range of altitude between $3 \mathrm{~km}$ and $7.5 \mathrm{~km}$, where we assume a purely molecular atmosphere. The expression for $\mathrm{SR}_{\mathrm{app}, \text { norm }}$ is as follows:

$\mathrm{SR}_{\text {app,norm }}=k \times \mathrm{SR}_{\text {app }}=\frac{\sum_{z=3.0 \mathrm{~km}}^{z=7.5 \mathrm{~km}} \beta_{\text {Rayleigh }}\left(z_{m}\right)}{\sum_{z=3.0 \mathrm{~km}}^{z=7.5 \mathrm{~km}}(X(z))} \times \mathrm{SR}_{\mathrm{app}}$.

In our case, a typical normalization factor of $k=1.011 \pm$ 0.004 was found.

The backscattered signal associated with cirrus clouds exhibits a sharp enhancement of up to 100 times with respect to the molecular scattering values at those altitudes (Seifert et al., 2007). Thus, the edges of the cirrus clouds are characterized by both a sharp increase and a sharp decrease. The cloud base and top altitudes, respectively $z_{\text {base }}$ and $z_{\text {top }}$, can be derived using the following criterion based in Goldfarb et al. (2001):

$\mathrm{SR}_{\mathrm{app}, \text { norm }}$ should be higher than a threshold value $t_{\mathrm{SR}}$, which is defined as

$t_{\mathrm{SR}}=1+3 \times(\Delta \mathrm{SR})$,

where the uncertainty $\Delta \mathrm{SR}$ is, according to Russel et al. (1979), calculated as

$\frac{\Delta \mathrm{SR}}{\mathrm{SR}_{\mathrm{app}, \text { norm }}}=\frac{\sqrt{N}}{N-B}=\frac{\sqrt{N_{\mathrm{p}}+B}}{N_{\mathrm{p}}}$,

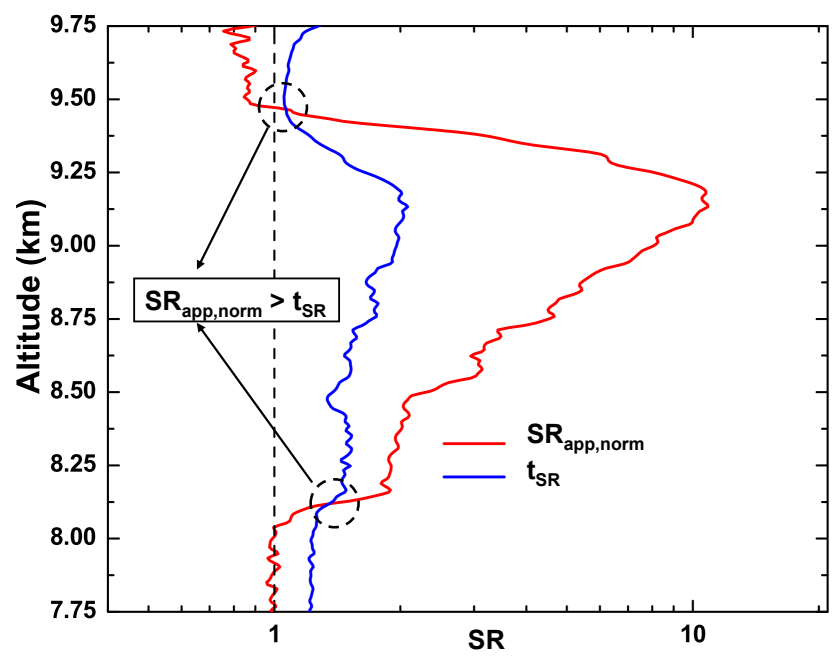

Fig. 3. Criterion to determine both the base and top heights from the apparent scattering ratio profile (red line) through threshold values (blue line).

where $N$ is a combination of the backscattered number of photons $N_{\mathrm{p}}$ and the parasite signal from the sky background $B$ that corresponds to the average number of photons in the last $10 \mathrm{~km}$ of the measured signal.

The factor 3 in Eq. (3) is chosen to obtain a significant cloud detection at $99 \%$ over the $\mathrm{SR}_{\text {app,norm }}$ profile (Goldfarb et al., 2001). The procedure mentioned above is illustrated in Fig. 3, where the blue line represents the correspondent threshold profile over the $\mathrm{SR}_{\text {app,norm }}$ profile (red line). According to this figure, the base and top are localized at $\sim 8.13$ and $9.40 \mathrm{~km}$, respectively.

The mid-cloud height $z_{\text {med }}$ is defined as the geometric center of a cirrus cloud, i.e., the arithmetic mean of $z_{\text {base }}$ and $z_{\text {top }}$; and it is directly associated with the corresponding temperature of a radiosonde profile, denominated $T_{\mathrm{zmed}}$ for consistency. The number of layers was obtained by identifying successive regions where abrupt variations of the signal (as described before) could potentially be associated with the cloud base and top.

The individual (noisy) backscattering profiles shall now be grouped according to the above-presented geometrical features of the cloud layers. For stationary atmospheric conditions, the backscattered photons hit the sensor following a stochastic Poisson process, and sampling over long enough periods provide a better statistical estimation of the cirrus cloud physical properties. However, cirrus clouds are composed of complex structures due to wind shears. As the clouds are very inhomogeneous spatially, different types of cirrus clouds can be present simultaneously in different layers and the morphology of the clouds in the lidar FOV can also vary greatly in this unique cloud system. As a result, long sampling periods would smear this information and compromise any climatology studies. In order to deal with 
this variability, we used a method consisting in adjusting the integration time by clustering similar cloud parameters in the acquisition sequence. This procedure is described in Hoareau et al. (2009). To identify discontinuities in cirrus cloud features in the present study, two complementary time series were investigated: the optical depth $\tau_{\mathrm{cir}}(\mathrm{L})$ and the geometrical thickness CT(L) for a given cirrus layer L. If cloud thickness changed significantly, it was interpreted as an indication of a fundamental change of the cloud characteristics. Additionally, if only optical characteristics changed, then the optical depth may have been sensitive to it. The altitude range was restrained to the extreme values of the base and top altitudes of the cirrus clouds identified previously (between 8 and $11.5 \mathrm{~km}$, as presented in Fig. 1).

\subsubsection{Transmittance method}

Approximate values of the optical depth $\tau_{\text {cir }}(\mathrm{L})$ of a cirrus layer $\mathrm{L}$ were derived from its transmittance $\mathrm{TT}(\mathrm{L})$ using the ratio of the apparent lidar SR values above and below the cloud layer ${ }^{1}$, where a clear atmosphere with purely molecular scattering is assumed (Cadet et al., 2005). This transmittance is defined as

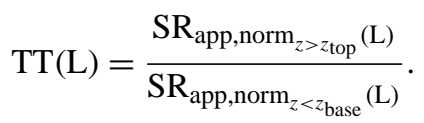

The TT(L) values are averaged over a given altitude range above $z_{\text {top }}$ and below $z_{\text {base }}$. The SR is averaged in the layer (with free aerosol atmosphere characteristics) of $1 \mathrm{~km}$ thickness. Above the cloud layer, one can observe in general a

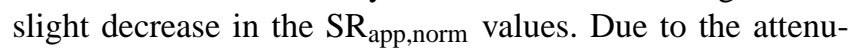
ation of the laser pulse, the experimental signal (numerator of Eq. 1) decreases while the signal, as predicted from a fit in the free atmosphere under the cloud layer (denominator of Eq. 1), does not take this effect into account. This attenuation is modeled by Eq. (5).

In some cases, the region between two layers is very narrow (typically less than $1 \mathrm{~km}$ ) and possibly suffers cloud overlap and mixing or the influence of residual aerosols. In this case, as there was not enough overhead to draw a reasonable average value, we used the minimum $S_{\text {app,norm value in }}$ this range in the calculation. This case is schematically illustrated in Fig. 4a and Fig. 4b represents a real case depicted in Fig. 4a with the measured signal fitted to the denominator $\beta_{\text {Rayleigh }}\left(z_{m}\right)$ of Eq. (1) in the above-cited $3.0-7.5 \mathrm{~km}$ range.

Notice in this case the two cloud layers are separated by a "free-aerosol atmosphere" region about $0.3 \mathrm{~km}$ (inset in Fig. $4 \mathrm{~b}$ ), which recalls the fact mentioned above in considering the minimum $\mathrm{SR}_{\mathrm{app}, \text { norm }}$ value.

The optical depth $\tau_{\text {cir }}(\mathrm{L})$ of the layer $\mathrm{L}$ is then calculated from the inferred transmittance using its definition:

$\tau_{\text {cir }}(\mathrm{L})=-0.5 \times(\ln (\mathrm{TT}(\mathrm{L})))$.

\footnotetext{
${ }^{1}$ This procedure is an approach for the transmittance method described by Young (1995) and detailed in Chen et al. (2002).
}

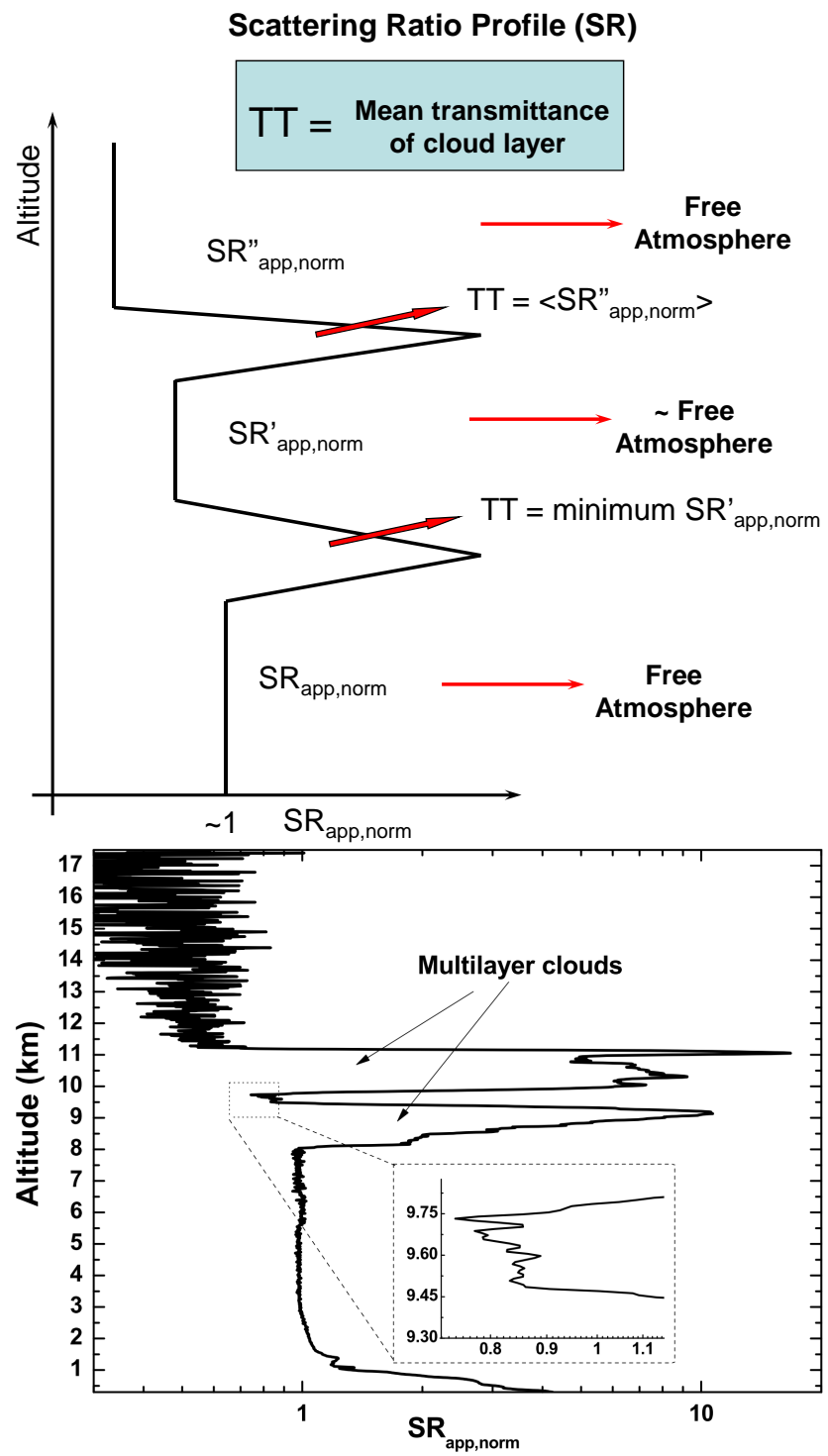

Fig. 4. (a) Criterion for obtaining the transmittance of cloud layers through SR' app,min and < SR “" app,norm $>$ on the first and second cloud, respectively; (b) typical $\mathrm{SR}_{\mathrm{app} \text {,norm }}$ signal profile also showing a inset to detail the "free-aerosol atmosphere" region between two layers.

The geometrical cloud thickness CT(L) is readily calculated as the difference between the values of the top and of base altitudes $z_{\text {base }}$ and $z_{\text {top }}$.

\subsubsection{Lanzante method}

Discontinuities in the time series of $\tau_{\mathrm{cir}}$ and CT were identified using the test of non-stationarity of the measurements due to a change in the dispersion (variance). The procedure applied was one method designed to determine the multiple change-points in arbitrary series of values (Lanzante, 1996) and was already applied for cirrus clouds (Hoareau 

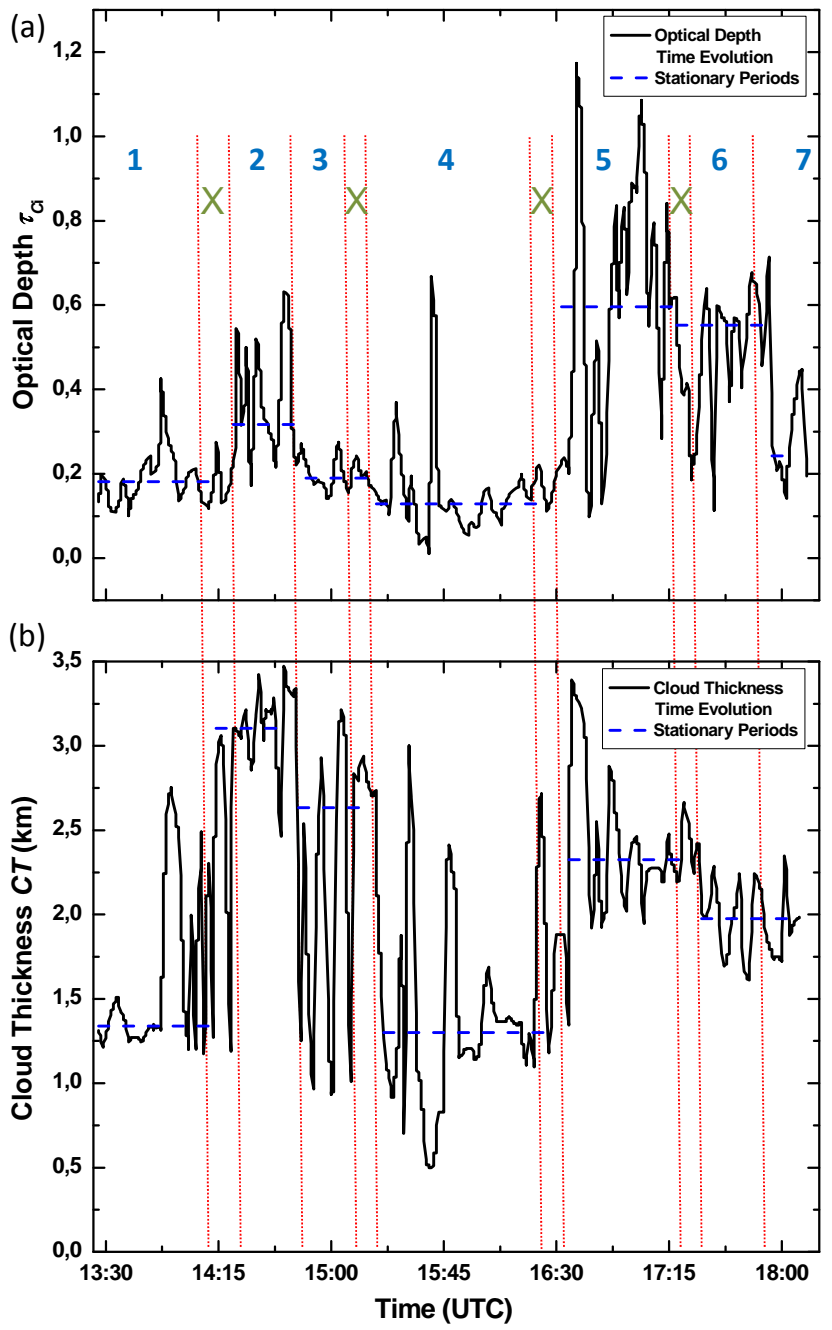

Fig. 5. Variation in time of (a) optical depth $\left(\tau_{\text {cir }}\right)$ and (b) cloud (geometrical) thickness (CT) for the altitude range between 8 and $11.5 \mathrm{~km}$ height as obtained from the MSP-lidar system observations. The black continuous line represents the variations on $\tau_{\text {cir }}$ and CT. The blue horizontal dashed lines represent the medians that define the stationary periods. Any contrary trend as verified simultaneously between the $\tau_{\text {cir }}$ and CT values corresponding to the interval marked as green " $\mathrm{X}$ " were removed from the sequence.

et al., 2012); it is based on a nonparametric statistical test (Wilcoxon-Mann-Whitney significance test) followed by an adjustment of the median. A refining procedure compares the variation of $\tau_{\mathrm{cir}}$ and $\mathrm{CT}$ and discards the data intervals where a contrary trend between these variables is found. Fig. 5 shows an example of the results obtained from the data acquired on 11 June 2007: (a) optical depth $\left(\tau_{\text {cir }}\right)$ and (b) cloud (geometrical) thickness (CT) for the altitude range between 8 and $11.5 \mathrm{~km}$ at São Paulo, Brazil, from the MSP-lidar system. The coherent cloud scenes are represented by the black solid line and the medians by the blue dashed lines defining the stationary periods. As mentioned before, when any diver-

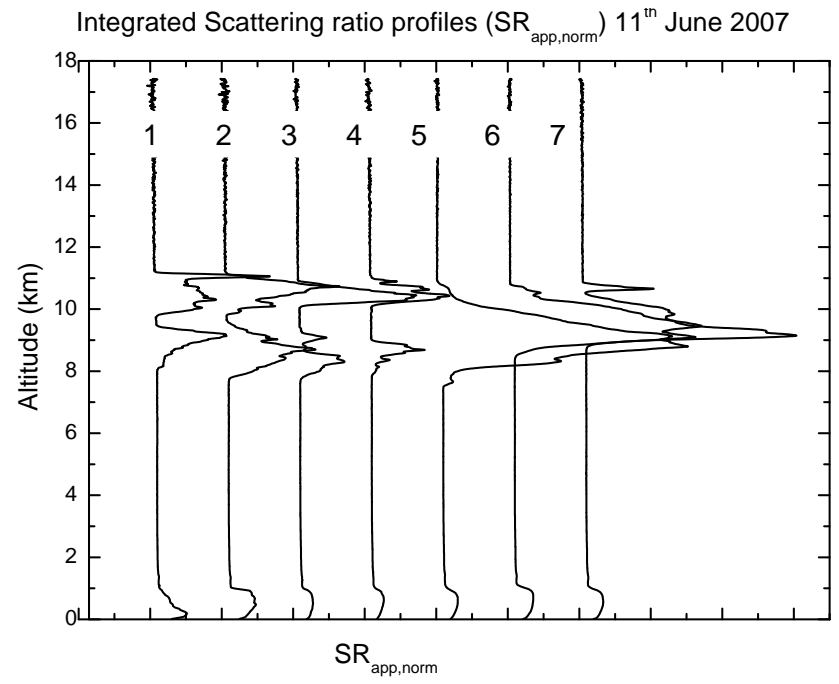

Fig. 6. Integrated scattering ratio $\left(\mathrm{SR}_{\mathrm{app}, \text { norm }}\right)$ profiles on 11 June 2007 corresponding to the respective stationary periods, determined by applying the statistical method suggested by Lanzante (1996). Is this case, seven independent profiles of SR were obtained.

gent tendency is verified simultaneously between the $\tau_{\text {cir }}$ and $\mathrm{CT}$ values, the corresponding interval is marked as a green " $\mathrm{X}$ " and then removed from the sequence. After applying this procedure, seven periods were identified. These periods correspond to those shown in Fig. 1.

The $\mathrm{SR}_{\mathrm{app} \text {,norm }}$ profile for each of these periods with stationary cloud properties is calculated by averaging all of the eligible individual profiles in a given interval. An example of resulting averaged $\mathrm{SR}_{\text {app,norm }}$ profiles is displayed in Fig. 6, corresponding to the seven periods identified in Fig. 5. These profiles were used to retrieve the optical cloud characteristics, as the values of the LR and the optical depth $\tau_{\text {cir }}$ associated with each individual cirrus.

\subsection{Retrieval of cirrus physical and optical characteristics}

In order to determine a reliable LR as a main optical property, the analysis of period-averaged $\mathrm{SR}_{\mathrm{app} \text {,norm }}$ profiles had continued to rely on the already mentioned transmittance method (Young, 1995; Chen et al., 2002). The final LR was calculated for each cloud layer through an iterative process updating the $\tau_{\text {cir }}$ and SR values until a stable value of LR was achieved. The iterative part of the process is displayed in the right panel of Fig. 7 and is described in detail in the following section.

\subsubsection{Determination of lidar ratio (LR) estimates by iterative processing}

For the altitudes $Z_{\mathrm{L}}$ of the cirrus layers $\mathrm{L}$, the respective lidar ratio $\operatorname{LR}\left(z_{\mathrm{L}}\right)$ can be calculated (by the equation described in Goldfarb et al., 2001 and also in Cadet et al., 2003), starting 

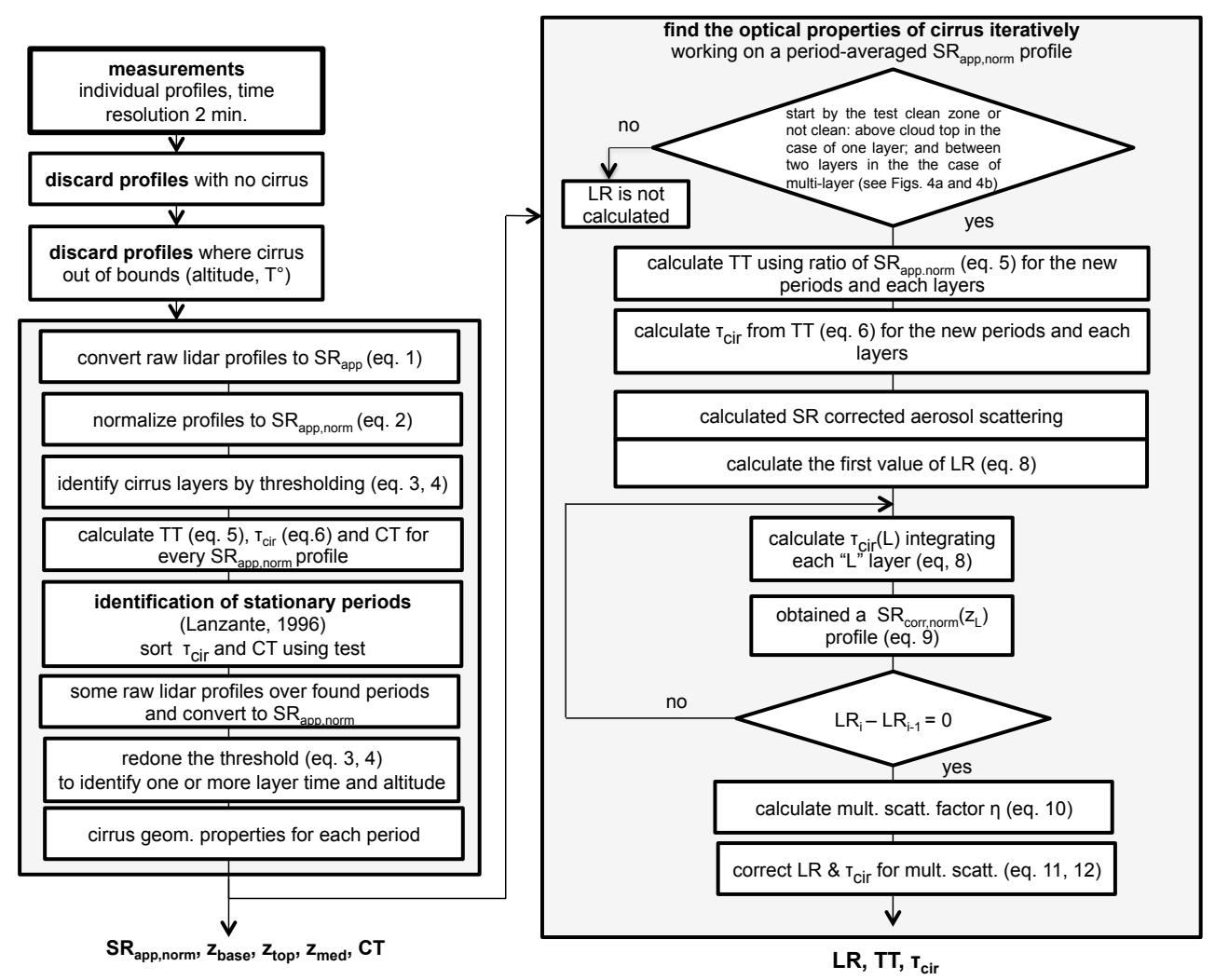

Fig. 7. Schematic flowchart showing the main steps of the methodology applied to obtain macrophysical and optical properties of cirrus clouds.

from the optical depth, defined as the local integral of the extinction coefficient, $\alpha\left(Z_{\mathrm{L}}\right)$ :

$$
\tau_{\text {cir }}(\mathrm{L})=\int_{z_{\text {base }}(\mathrm{L})}^{z_{\text {top }}(\mathrm{L})} \alpha\left(z_{\mathrm{L}}\right) d z_{\mathrm{L}} .
$$

The extinction coefficient $\alpha\left(Z_{\mathrm{L}}\right)$ can be estimate as the product of LR and the backscattering ratio at the considered altitudes $Z_{\mathrm{L}}$ :

$$
\begin{aligned}
& \tau_{\text {cir }}(\mathrm{L})=\int_{z_{\text {base }}}^{z_{\text {top }}} \alpha(z) d z=\operatorname{LR}\left(z_{\mathrm{L}}\right) \times \sigma_{\text {Rayleigh }} \int_{\text {zbase }}^{z_{\text {top }}} n_{\text {air }}(z) \\
& \times\left(\operatorname{SR}_{\text {corr,norm }}(z)-1\right) d z,
\end{aligned}
$$

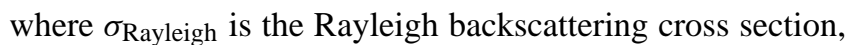
and $n_{\text {air }}(z)$ is the density of air, calculated using vertical profiles of temperature and pressure provided by the radiosonde observations. However, the scattering ratio ${ }^{2}$ is not measured

\footnotetext{
${ }^{2}$ To demonstrate the Eq. (8), we use the conventional scattering ratio definition and omit the "corr,norm" term by considering the approximation $\mathrm{SR}_{\text {corr,norm }} \approx \mathrm{SR}$ is still valid: $\mathrm{SR}=\left(\beta_{\text {Rayleigh }}+\right.$ $\left.\beta_{\text {Mie }}\right) / \beta_{\text {Rayleigh }}$, so $\beta_{\text {Mie }}=\beta_{\text {Rayleigh }}$ (SR-1). Inside of the cloud, the lidar ratio can be approximated by $\mathrm{LR}=\alpha / \beta \approx \alpha / \beta_{\text {Mie }}$, once
}

directly with the lidar; instead, we have to use the apparent value $\mathrm{SR}_{\mathrm{app}, \text { norm }}(z)$ corrected for the cirrus particle scattering $\tau_{\text {cir }}$. This correction can be done using the assumed linear relation with LR that is not yet estimated. So we first have to use an approximate value of LR and then through an iterative process improve both LR and SR. The first LR obtained by Eq. (8) was assumed as default value for the cloud layer and was used to calculate $\tau_{\text {cir }}$ (also using Eq. 8). From this procedure, one can obtained a better estimate of SR profile (Eq. 9) - $\mathrm{SR}_{\mathrm{corr}, n o r m}(z)$, that represents the true corrected scattering ratio from the apparent one:

$\operatorname{SR}_{\text {corr,norm }}\left(z_{\mathrm{L}}\right)=\frac{\operatorname{SR}_{\text {app,norm }}\left(z_{\mathrm{L}}\right)}{e^{-2 \tau_{\text {cir }}(\mathrm{L})}}$.

The original apparent scattering ratio is divided by the exponential corresponding to the (two-way) attenuation of the laser pulse after crossing the layer $\mathrm{L}$.

Finally, the new $\mathrm{SR}_{\text {corr,norm }}$ profile can be used to recalculate a new LR applying the Eq. (8) again (retaining the same $\tau_{\text {cir }}$ determined on the transmittance method). This iterative process is performed until it converges to a stable solution of LR, for instance, when LR has variations only on the third digit after comma.

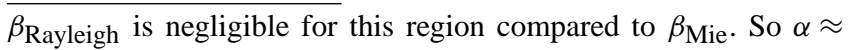
$\mathrm{LR} \beta_{\mathrm{Mie}}=\mathrm{LR} \beta_{\text {Rayleigh }}(\mathrm{SR}-1)=\mathrm{LR} \sigma_{\text {Rayleigh }} \eta_{\text {air }}(\mathrm{SR}-1)$. 
As summarized in the flowchart of Fig. 7, for each cirrus layer, we identified the following macrophysical properties: base and top altitudes $z_{\text {base }}$ and $z_{\text {top }}$, the respective midheight $z_{\text {med }}$, and cloud thickness CT. Using radiosonde observation profiles, we were also able to derive the associated temperatures $T_{\text {zbase }}, T_{\text {ztop }}$ and $T_{\text {zmed }}$. Finally, some relevant optical properties, including the optical depth $\tau_{\text {cir }}$ and lidar ratio LR, were also retrieved for each cirrus layer with associated uncertainties.

\subsection{Multiple scattering effects}

Depending on the composition (ice and water), density, and thickness of clouds, multiple scattering can contribute nonnegligibly to the lidar signal (Eloranta, 1998). The effective optical depths retrieved by a lidar overestimated as retarded photons still contribute to the signal (Josset et al., 2012). Several approaches and formalisms have been proposed to correct for this effect (Platt, 1973; Eloranta, 1998; Bissonette, et al., 2005; Mitrescu, 2005; Giannakaki et al., 2007) and have found that multiple scattering is related primarily to the optical depth. In this sense, the values of $\tau_{\text {cir }}$ or LR obtained do not necessarily represent the effective ones. To settle the effective correction, we use a factor $\eta$ on the observed backscatter coefficient as defined by Platt (1973). For a cirrus layer $\mathrm{L}$ of a given optical depth $\tau_{\text {cir }}(\mathrm{L}), \eta(\mathrm{L})$ can be calculated (Chen et al., 2002):

$\eta(\mathrm{L})=\frac{\tau_{\text {cir }}(\mathrm{L})}{\exp \left(\tau_{\mathrm{cir}}(\mathrm{L})\right)-1}$.

This formula gives a description of the increase of multiple scattering effects with optical depth. For most of the cirrus layers studied in this work, this factor should not be less than 0.6 , since the deepest cloud had no more than 0.92 of optical depth (Table 2). Effective values for the optical depth $\tau_{\text {cir }}(\mathrm{L})$ and lidar ratio $\operatorname{LR}\left(z_{\mathrm{L}}\right)$ are given by the following calculations (Josset et al., 2012):

$\tau_{\text {eff }}(\mathrm{L})=\eta(\mathrm{L}) \times \tau_{\text {cir }}(\mathrm{L})$

$\operatorname{LR}_{\text {eff }}\left(z_{\mathrm{L}}\right)=\eta(\mathrm{L}) \times \operatorname{LR}\left(z_{\mathrm{L}}\right)$.

Apparent values of $\tau_{\text {cir }}$ and LR and the respective corrected ones (i.e., the effective values) are summarized in Table 2.

\section{Uncertainty analysis}

\subsection{Optical depth and lidar ratio uncertainties}

Our error calculations are based on standard lidar analyses already described in Russel et al. (1979). Since the lidar signal covers a very high dynamic range corresponding to several orders of magnitude, it is not manageable by the electronic acquisition systems. It requires the use of simultaneous photon counting and analogue acquisition for the low and the high signals. Then it consists in a separation of the optical signal in two parts, corresponding to the high and the low altitudes respectively. Since cirrus clouds occur in high altitudes, photo-counting signals are considered, and the main uncertainty in our lidar measurements is directly related to photon noise. In this sense, the standard errors associated to the main optical parameters are proportional to the square root of the number of photons received, as described by Eq. (4).

Following this formulation allows us to obtain the uncertainties for the transmittance of each layer:

$$
\frac{\Delta \mathrm{TT}(\mathrm{L})}{\mathrm{TT}(\mathrm{L})}=\sqrt{\left(\frac{\Delta \mathrm{SR}(z)_{1}}{\operatorname{SR}_{\text {app,norm }}(z)_{1}}\right)^{2}+\left(\frac{\Delta \mathrm{SR}(z)_{2}}{\mathrm{SR}_{\mathrm{app}, \text { norm }}(z)_{2}}\right)^{2}},
$$

which the indices "1" and "2" indicate, respectively, values below the base and above the top of cloud, i.e., the regions where the Rayleigh signal is predominant and the noise comes exclusively from the photon counting.

Equation (6) allows us to calculate the uncertainty for the optical depth $\tau_{\text {cir }}$ and can be written as follows:

$\Delta \tau_{\text {cir }}(z)=\frac{1}{2} \frac{\Delta \mathrm{TT}(z)}{\mathrm{TT}(z)}$.

Finally, the relative error in the lidar ratio LR can be considered the same for the optical depth $\tau_{\text {cir }}$ (due to the linear relation between $\tau_{\text {cir }}$ and LR on Eq. 9):

$\delta \mathrm{RL}=\frac{\Delta \tau_{\mathrm{cir}}(z)}{\tau_{\mathrm{cir}}(z)} ;$

and the error for LR is given by

$\Delta \mathrm{RL}=\mathrm{RL} \times \delta \mathrm{RL}$.

\subsection{Correction of uncertainties taking account the multi-scattering effect}

After applying the multi-scattering correction for $\tau_{\text {cir }}$ and LR to obtain the effective values, the respective corrections for the uncertainties should be made. It can be done by using standard propagation in error analysis for the Eqs. (10), (11) and (12).

$\Delta \tau_{\text {eff }}(z)=\sqrt{(\eta(z))^{2}\left(\Delta \tau_{\text {cir }}(z)\right)^{2}+\left(\tau_{\text {cir }}(z)\right)^{2}(\Delta \eta(z))^{2}}$
$\Delta \operatorname{LR}_{\text {eff }}(z)=\sqrt{(\eta(z))^{2}(\Delta \operatorname{LR}(z))^{2}+(\operatorname{LR}(z))^{2}(\Delta \eta(z))^{2}}$.

\section{Discussion of the cirrus properties obtained}

The methodology presented here was applied to the lidar data series acquired on 11 June 2007 with the lidar system localized at the Center for Lasers and Applications/IPEN (metropolitan region of São Paulo, SP, Brazil). Table 1 presents the macrophysical properties and Table 2 the associated optical properties found for the measured cirrus clouds 
Table 1. Macrophysical properties of cirrus observed over São Paulo City on 11 June 2007.

\begin{tabular}{|c|c|c|c|c|c|c|c|}
\hline Periods & $z_{\text {base }}(\mathrm{km})$ & $z_{\text {top }}(\mathrm{km})$ & $z_{\text {med }}(\mathrm{km})$ & $T_{\text {zbase }}\left({ }^{\circ} \mathrm{C}\right)$ & $T_{\text {ztop }}\left({ }^{\circ} \mathrm{C}\right)$ & $T_{\text {zmed }}\left({ }^{\circ} \mathrm{C}\right)$ & $\mathrm{CT}(\mathrm{km})$ \\
\hline \multicolumn{8}{|c|}{ Multilayer cloud - First Layer } \\
\hline 1 & 8.05 & 9.47 & 8.76 & -26.77 & -37.76 & -32.47 & 1.42 \\
\hline 2 & 7.75 & 9.56 & 8.65 & -24.08 & -38.50 & -31.58 & 1.81 \\
\hline 3 & 7.69 & 9.40 & 8.54 & -23.61 & -37.17 & -30.74 & 1.70 \\
\hline 4 & 7.85 & 9.01 & 8.43 & -25.02 & -34.49 & -29.92 & 1.15 \\
\hline \multicolumn{8}{|c|}{ Multilayer cloud - Second Layer } \\
\hline 1 & 9.79 & 11.19 & 10.49 & -40.52 & -52.87 & -46.66 & 1.4 \\
\hline 2 & 9.84 & 11.12 & 10.48 & -41.01 & -52.24 & -46.59 & 1.28 \\
\hline 3 & 10.05 & 10.89 & 10.47 & -42.99 & -49.98 & -46.56 & 0.84 \\
\hline 4 & 10.09 & 11.01 & 10.49 & -43.33 & -51.15 & -47.2 & 0.91 \\
\hline \multicolumn{8}{|c|}{ Monolayer cloud } \\
\hline 5 & 7.51 & 10.76 & 9.13 & -21.88 & -48.91 & -35.47 & 3.27 \\
\hline 6 & 8.44 & 10.74 & 9.59 & -30.09 & -48.8 & -39.17 & 2.32 \\
\hline 7 & 8.73 & 10.83 & 9.77 & -32.19 & -49.39 & -40.64 & 2.12 \\
\hline
\end{tabular}

Table 2. Optical properties of cirrus observed over São Paulo City on 11 June 2007.

\begin{tabular}{|c|c|c|c|c|c|}
\hline Periods & TT & $\tau_{\text {cir_app }}$ & $\tau_{\text {cir_eff }}$ & $\mathrm{LR}_{\text {app }}(\mathrm{sr})$ & $\mathrm{LR}_{\text {eff }}(\mathrm{sr})$ \\
\hline \multicolumn{6}{|c|}{ Multilayer cloud - First Layer } \\
\hline 1 & $0.76 \pm 0.03$ & $0.14 \pm 0.02$ & $0.13 \pm 0.02$ & $28 \pm 4$ & $26 \pm 4$ \\
\hline 2 & $0.65 \pm 0.02$ & $0.21 \pm 0.01$ & $0.19 \pm 0.01$ & $22 \pm 1$ & $19 \pm 1$ \\
\hline 3 & $0.83 \pm 0.03$ & $0.09 \pm 0.02$ & $0.09 \pm 0.02$ & $25 \pm 4$ & $24 \pm 4$ \\
\hline 4 & $0.84 \pm 0.03$ & $0.09 \pm 0.02$ & $0.08 \pm 0.02$ & $35 \pm 5$ & $33 \pm 5$ \\
\hline \multicolumn{6}{|c|}{ Multilayer cloud - Second Layer } \\
\hline 1 & $0.58 \pm 0.04$ & $0.28 \pm 0.03$ & $0.24 \pm 0.03$ & $37 \pm 4$ & $32 \pm 4$ \\
\hline 2 & $0.5 \pm 0.02$ & $0.35 \pm 0.02$ & $0.29 \pm 0.02$ & $39 \pm 3$ & $32 \pm 3$ \\
\hline 3 & $0.65 \pm 0.02$ & $0.22 \pm 0.02$ & $0.19 \pm 0.02$ & $38 \pm 4$ & $34 \pm 4$ \\
\hline 4 & $0.76 \pm 0.02$ & $0.14 \pm 0.02$ & $0.13 \pm 0.02$ & $74 \pm 13$ & $69 \pm 12$ \\
\hline \multicolumn{6}{|c|}{ Monolayer cloud } \\
\hline 5 & $0.16 \pm 0.01$ & $0.92 \pm 0.01$ & $0.56 \pm 0.01$ & $20 \pm 1$ & $12 \pm 1$ \\
\hline 6 & $0.34 \pm 0.01$ & $0.54 \pm 0.01$ & $0.41 \pm 0.01$ & $20 \pm 2$ & $15 \pm 2$ \\
\hline 7 & $0.48 \pm 0.01$ & $0.37 \pm 0.01$ & $0.30 \pm 0.01$ & $19 \pm 1$ & $16 \pm 1$ \\
\hline
\end{tabular}

divided into seven stationary periods, as mentioned before. The periods 1-4 correspond to multilayer clouds and 5-7 to a monolayer cloud (see Figs. 1 and 6). For the multilayer cases, the lowest layers present bases between 7.69 and $8.05 \mathrm{~km}$ and tops between 9.01 and $9.56 \mathrm{~km}$, while the highest layers present cloud bases between 9.79 and $10.09 \mathrm{~km}$ and tops between 10.89 and $11.19 \mathrm{~km}$. For the monolayer clouds, the bases range between 7.51 and $8.73 \mathrm{~km}$ and the tops between 10.74 and $10.83 \mathrm{~km}$. This indicates that the distinct and thinner clouds, observed for the first four periods, are followed by a single thicker cloud layer during the last three periods. It can be clearly observed in Figs. 1 and 6. Obviously, this behavior has a direct impact on the optical properties of clouds, as seen in Table 2. For instance, the optical depths do not exceed 0.30 (after multi-scattering correction) for the first four periods while for the last three periods one can find an optical depth of 0.56 . At the same time, one can notice the importance of taking into account the multi-scattering process and the correspondent corrections that can produce differences of up to $39 \%$ between the apparent $\left(\tau_{\text {cir_app }}\right)$ and effective ( $\tau_{\text {cir_eff }}$ ) optical depths (period 6 for instance; see in Table 2 ).

Cirrus optical depth $\left(\tau_{\text {cir }}\right)$ is a valuable indicator for which category the clouds can be classified. According to Sassen (2002), the clouds appearing during the first four periods can be classified as thin cirrus $\left(0.03<\tau_{\text {cir }}<0.30\right)$, while the last three periods are mostly composed of thick cirrus 
$\left(0.3<\tau_{\text {cir }}<3.0\right)$. Subvisible cirrus $\left(\tau_{\text {cir }}<0.03\right)$ were not detected in this case.

Cloud temperature information was obtained from radiosonde balloons, which were launched twice a day at 00:00 UTC and 12:00 UTC near the Campo de Marte airport, located approximately $12 \mathrm{~km}$ from the MSP-lidar system. For the present analysis, we considered the data at 12:00 UTC for that day as closest to the time period when the lidar measurements were performed. Temperature changes during the lidar measurements are not available and cirrus changes cannot be correlated with short-term temperature changes. While simultaneous temperature and lidar measurements using Raman techniques would be valuable, the information of mean temperature is still important. The temperature in the mid-cloud heights $\left(T_{\text {zmed }}\right)$ ranges between -47.2 and $-29.9^{\circ} \mathrm{C}$ (see Table 1), indicating that some of these clouds may present mixed phases as mentioned in Giannakaki et al. (2007), and a possible impact of water clouds should not be completely disregarded. However, information about different phases in clouds is usually obtained using depolarization channels (Chen et al., 2002; Lampert et al., 2010) that in our case were not available.

The lidar ratio derived from the multilayer cases reveals good stability for the first three periods: an average value of $25 \mathrm{sr}$ is obtained for the lowest cloud layer, and $38 \mathrm{sr}$ for the upper one, indicating different optical characteristics. The fourth period shows a significant change of the LR value for the upper cloud, indicating a possible presence of different types of crystals when compared with the first three periods. In this case, the last three periods represent a collapse of the previously detected two-layered clouds to form a monolayer. This monolayer presents LR values around $20 \mathrm{sr}$, indicating the appearance of crystals with different shapes and orientations, again followed by some phase changes.

Some authors have tried to correlate the respective midcloud temperature with lidar ratios, although such a clear dependence is not obvious (Seifert et al., 2007). Whiteman et al. (2004), for example, verified a general trend of an increase in lidar ratios with decreasing temperatures for their observations carried out at the Andros Islands, Bahamas. They found values of about $15-17 \pm 10 \mathrm{sr}$ at $-30^{\circ} \mathrm{C}, 22 \pm 8 \mathrm{sr}$ at $-50^{\circ} \mathrm{C}$, and $28-33 \pm 12 \mathrm{sr}$ at temperatures around $-70^{\circ} \mathrm{C}$ when excluding hurricane-influenced cases. In the same way, lidar observations conducted in Taiwan from August 1999 to July 2000 presented by Chen et al. (2002) showed lidar ratios $\leq 50 \mathrm{sr}$ for $90 \%$ of measurements after multiple-scattering corrections. In the altitude ranges between $12 \mathrm{~km}\left(-50^{\circ} \mathrm{C}\right)$ to $15 \mathrm{~km}\left(-70^{\circ} \mathrm{C}\right)$, they found lidar ratios of about $35 \pm 15 \mathrm{sr}$. Platt et al. (2002), using the LIRAD method (combined lidar and infrared radiometry measurements; Platt, 1973) for observations acquired during the Maritime Continent Thunderstorm Experiment (MCTEX) close to Australia, retrieved lidar ratios ranging from 42 to $74 \mathrm{sr}$ for temperatures between $-45^{\circ} \mathrm{C}$ and $-70^{\circ} \mathrm{C}$, respectively. Recent analyses using the ocean surface observations from CloudSat radar and data from Cloud Aerosol Lidar with Orthogonal Polarization (CALIOP) on board the Cloud Aerosol Lidar and Infrared Pathfinder Observations (CALIPSO) (Winker et al., 2010), combined in the Synergized Optical Depth of Aerosol (SODA) algorithm, were performed by Josset et al. (2012). They found, for the preliminarily selected data, lidar ratios varying between 30 and $34 \mathrm{sr}$ respectively for the temperature range of $-70^{\circ} \mathrm{C}$ and $-40^{\circ} \mathrm{C}$ with a maximum slightly higher than $34 \mathrm{sr}$ at $-50^{\circ} \mathrm{C}$. In our case, the effective lidar ratios $\left(\mathrm{LR}_{\mathrm{eff}}\right.$ ) do not exceed $35 \mathrm{sr}$ (only for period 4, LR value of $69 \pm 12 \mathrm{sr}$ is reported) for the early mentioned range of temperature, although no clear dependence between these variables can be established again.

This variability can be related to the different types of clouds studied in different campaigns associated with geographical variations. Although there seems to be a connection between lidar ratio and temperature, which could in turn lead to a different ice nucleation process with distinct optical properties of ice crystals, a detailed analysis allowing a cirrus-type classification including origin and formation mechanisms information is needed. However, this is beyond the scope of this manuscript and it will be addressed in a future publication.

All the comparisons made with our case study cannot be considered as a validation for our methodology, although it is a good indication that the applications of our routines can retrieve reliable cirrus optical properties in operational conditions.

What is important to highlight here is also the ability to retrieve lidar ratio values for different cirrus formations in a consistent way with an alternative and robust methodology. The approach inferred here is to be implemented in the near future to generate a nine-year (2004-2012) lidar-retrieved cirrus properties database over São Paulo that will determine the cirrus cloud climatology and establish an operational routine analysis of this kind of clouds.

\section{Conclusions}

An alternative and robust method to calculate lidar ratios for distinct cloud layers has been presented. The retrieved lidar ratios are shown to be somewhat consistent with those obtained by other authors in different contexts for a given range of (mid-cloud) temperatures. The robustness of this method is based on a previous detailed selection of cirrus occurrence periods and the further application of nonparametric statistics to determine the so-called stationary periods. The backscattering ratio profiles for those periods produce the required cirrus macrophysical and optical parameters. The iterative routine will assure the stability of lidar-retrieved ratios as well as their optical depths. This last variable also determines, in a simple way, the multiple scattering factor, applied for a final estimation of LR values. Once the effectiveness of this method is verified, it can be fully automated in routine 
process. Also, it will permit future analysis for a long-term, lidar-measured cirrus properties database to obtain the climatology of cirrus clouds in the São Paulo region, the first of this type performed in Brazil.

Acknowledgements. This work has been supported by the Conselho Nacional de Desenvolvimento Científico e Tecnológico (CNPq). The authors thank their colleagues (especially Carmen Córdoba-Jabonero from Spain) for continuing support and fruitful discussion about the contents of this manuscript. The authors also would like to thank Fapesp for supporting the cooperation projects under the grants 2011/21114-9 and 2012/00809-1, which proportioned important discussions for the conclusion of this manuscript. Finally, a special acknowledgement is extended to the referees for their assistance in evaluating this paper.

Edited by: V. Amiridis

\section{References}

Ackermann, J.: The extinction-to-backscatter ratio of tropospheric aerosol: a numerical study, J. Atmos. Ocean. Technol., 15, 10431050, doi:10.1175/1520-0426, 1998.

Ansmann, A.: Molecular-Backscatter Lidar Profiling of the Volume-Scattering Coefficient in Cirrus, edited by: Lynch, D. K., Sassen, K., Starr, D.O'C and Stephens, G.: Cirrus, Oxford University Press, London, 197-210, 2002.

Ansmann, A., Riebesell, M., Wandinger, U., Weitkamp, C., Voss, E., Lahmann W., and Michaelis, W.: Combined Raman elasticbackscatter LIDAR for vertical profiling of moisture, aerosol extinction, backscatter, and LIDAR ratio, Appl. Phys., B55, 18-28, doi:10.1007/BF00348608, 1992.

Barnaba, F. and Gobbi, G. P.: Modeling the aerosol extinction versus backscatter relationship for lidar applications: maritime and continental conditions, J Atmos. Ocean. Technol., 21, 428-442, doi:10.1175/1520-0426(2004)021<0428:MTAEVB>2.0.CO;2, 2004.

Bissonnette, L. C., Roy, G., and Roy, N.: Multiple-scattering-based lidar retrieval: method and results of cloud probings, Appl. Opt., 44, 5565-5581, doi:10.1364/AO.44.005565, 2005.

Bucholtz, A.: Rayleigh-scattering calculations for the terrestrial atmosphere, Appl. Opt., 34, 15, 2765-2773, doi:10.1364/AO.34.002765, 1995.

Cadet, B., Goldfarb, L., Faduilhe, D., Baldy, S., Giraud, V., Keckhut, P., and Rechou, A.: A sub-tropical cirrus clouds climatology from Reunion Island $\left(21^{\circ} \mathrm{S}, 55^{\circ} \mathrm{E}\right)$ lidar data set, Geophys. Res. Lett., 30, 30.1-30.4, doi:10.1029/2002GL016342, 2003.

Cadet, B., Giraud, V., Haeffelin, M., Keckhut, P., Rechou, A., and Baldy, S.: Improved retrievals of the optical properties of cirrus clouds by a combination of lidar methods, Appl. Opt., 44, 17261734, doi:10.1364/AO.44.001726, 2005.

Chen, W. N., Chiang, C. W., and Nee, J. B.: Lidar ratio and depolarization ratio for cirrus clouds, Appl. Opt., 41, 6470-6476, doi:10.1364/AO.41.006470, 2002.

Das, S. K., Chiang, C. W., and Nee, J. B.: Characteristics of cirrus clouds and its radiative properties based on lidar observation over Chung-Li, Taiwan, Atmos. Res., 93, 723-735, doi:10.1016/j.atmosres.2009.02.008, 2009.
Draxler, R. R. and Rolph, G. D.: HYSPLIT (HYbrid Single-Particle Lagrangian Integrated Trajectory) Model access via NOAA ARL READY Website http://ready.arl.noaa.gov/HYSPLIT.php, NOAA Air Resources Laboratory, Silver Spring, MD, 2013.

Dupont, J.,-C, Haeffelin, M., Morille, Y., Noël, V., Keckhut, P., Winker, D., Comstock, J., Chervet, P. and Roblin, A.: Macrophysical and optical properties of mid-latitude high-altitude clouds from 4 ground-based lidars and collocated CALIOP observations, J. Geophys. Res., 115, D00H24, doi:10.1029/2009JD011943, 2010.

Eloranta, E. W.: Practical model for the calculation of multiply scattered lidar returns, Appl. Opt., 37, 2464-2472, doi:10.1364/AO.37.002464, 1998.

Fueglistaler, S., Wernli, H. and Peter, T.: Tropical troposphere-tostratosphere transport inferred from trajectory calculations, J. Geophys. Res., 109, D03108, doi:10.1029/2003JD004069, 2004.

Giannakaki, E., Balis, D. S., Amiridis, V., and Kazadzis, S.: Optical and geometrical characteristics of cirrus clouds over a Southern European lidar station, Atmos. Chem. Phys., 7, 5519-5530, doi:10.5194/acp-7-5519-2007, 2007.

Goldfarb, L., Keckhut, P., Chanin, M.-L., and Hauchecorne, A.: Cirrus climatological results from lidar measurements at OHP $\left(44^{\circ} \mathrm{N}, 6^{\circ} \mathrm{E}\right)$, Geophys. Res. Lett., 28, 1687-1690, doi:10.1029/2000GL012701, 2001.

Hallett, J., Arnott, W. P., Bailey, M. P., and Hallett, J. T.: Ice crystals in cirrus, edited by: Lynch, D. K., Sassen, K., Starr, D. O., and Stephens, G. L., Cirrus, 41-77. Oxford University Press, 2002.

Heymsfield, A. J.: Ice crystal terminal velocities, J. Atmos. Sci., 29, 1348-1357, 1972.

Heymsfield, A. J. and Platt, C. M. R.: A parameterization of the particle size spectrum of ice clouds in terms of the ambient temperature and the ice water content, J. Atmos. Sci., 41, 846-855, doi:10.1175/1520-0469(1984)041<0846:APOTPS > 2.0.CO;2, 1984.

Hoareau, C., Keckhut, P., Sarkissian, A., Baray, J.-L. and Durry, G.: Methodology for Water Monitoring in the Upper Troposphere with Raman Lidar at the Haute-Provence Observatory, J. Atmos. Ocean. Technol., 26, 2149-2160, doi:10.1175/2009JTECHA1287.1, 2009.

Hoareau, C., Keckhut, P., Baray, J.-L. , Robert, L., Courcoux, Y., Porteneuve, J., Vömel, H., and Morel, B.: A Raman lidar at la Reunion $\left(20.8^{\circ} \mathrm{S}, 55.5^{\circ} \mathrm{E}\right)$ for monitoring water vapor and cirrus distributions in the subtropical upper troposphere: preliminary analyses and description of a future system, Atmos. Meas. Tech., 5, 1333-1348, doi:10.5194/amt-5-1333-2012, 2012.

Josset, D., Pelon, J., Garnier, A., Hu, Y., Vaughan, M., Zhai, P.W., Kuehn, R., and Lucker, P.: Cirrus optical depth and lidar ratio retrieval from combined CALIPSO-CloudSat observations using ocean surface echo, J. Geophys. Res., 117, D05207, doi:10.1029/2011JD016959, 2012.

Keckhut, P., Hauchecorne, A., Bekki, S., Colette, A., David, C., and Jumelet, J.: Indications of thin cirrus clouds in the stratosphere at mid-latitudes, Atmos. Chem. Phys., 5, 3407-3414, doi:10.5194/acp-5-3407-2005, 2005.

Keckhut, P., Borchi, F., Bekki, S., Hauchecorne, A., and Silaouina, M.: Cirrus classification at mid-latitude from systematic lidar observations, J. Appl. Meteor. Clim., 45, 249-258, doi:10.1175/JAM2348.1, 2006. 
Klett, J. D.: Lidar Inversion with Variable Backscatter/Extinction Ratios, Appl. Opt. 24, 1638, doi:10.1364/AO.24.001638, 1985.

Lampert, A., Ritter, C., Hoffmann, A., Gayet, J.-F., Mioche, G., Ehrlich, A., Dörnbrack, A., Wendisch, M., and Shiobara, M.: Lidar characterization of the Arctic atmosphere during ASTAR 2007: four cases studies of boundary layer, mixed-phase and multi-layer clouds, Atmos. Chem. Phys., 10, 2847-2866, doi:10.5194/acp-10-2847-2010, 2010.

Landulfo, E., Papayannis, A., Artaxo, P., Castanho, A. D. A., de Freitas, A. Z., Souza, R. F., Vieira Junior, N. D., Jorge, M. P. M. P., Sánchez-Ccoyllo, O. R., and Moreira, D. S.: Synergetic measurements of aerosols over São Paulo, Brazil using LIDAR, sunphotometer and satellite data during the dry season, Atmos. Chem. Phys., 3, 1523-1539, doi:10.5194/acp-3-1523-2003, 2003.

Lanzante, J. R.: Resistant, robust and non-parametric techniques for the analysis of climate data: Theory and examples, including applications to historical radiosonde station data, Int. J. Climatol., 16, 1197-1226, doi:10.1002/(SICI)10970088(199611)16:11<1197::AID-JOC89>3.0.CO;2-L, 1996.

Li, J.-L., Waliser, D. E., Jiang, J. H., Wu, D. L., Read, W., Waters, J. W., Tompkins, A., Donner, L. J., Chern, J.-D., Tao, W.K., Atlas, R., Gu, Y., Liou, K. N., Del Genio, A., Khairoutdinov, M., and Gettelman, A.: Comparisons of EOS MLS cloud ice measurements with ECMWF analyses and GCM simulations: Initial Results, Geophys. Res. Lett., 32, L18710, doi:10.1029/2005GL023788, 2005.

Liou, K. N.: The Influence of Cirrus on Weather and Climate Process: A Global Perspective, Mon. Weather Rev., 114, 1167-1199, 1986.

Mitrescu, C.: Lidar model with parameterized multiple scattering for retrieving cloud optical properties, J. Quant. Spectrosc. Radiat. Transf., 94, 201-224, doi:10.1016/j.jqsrt.2004.10.006, 2005.

Montoux, N., Keckhut, P., Hauchecorne, A., Jumelet, J., Brogniez, H. and David, C.: Isentropic modeling of a cirrus cloud event observed in the mid latitude upper troposphere and lower stratosphere, J. Geophys. Res., 115, D02202, doi:10.1029/2009JD011981, 2010.

Nazaryan, H., McCormick, M. P., and Menzel, W. P.: Global characterization of cirrus clouds using CALIPSO data, J. Geophys. Res., 113, D16211, doi:10.1029/2007JD009481, 2008.

Platt, C. M. R.: Lidar and radiometric observations of cirrus clouds, J. Atmos. Sci., 30, 1191-1204, doi:10.1175/15200469(1973)030<1191:LAROOC>2.0.CO;2, 1973.

Platt, C. M. R., Young, S. A., Austin, R. T., Patterson, G. R., Mitchell, D. L. and Miller, S. D.: LIRAD observations of tropical cirrus clouds in MCTEX. Part I: Optical properties and detection of small particles in cold cirrus, J. Atmos. Sci., 59, 3145-3162, doi:10.1175/JAS2843sup11, 2002.

Petty, D., Comstock, J., and Tuner, D.: Cirrus Extinction and Lidar Ratio Derived from Raman Lidar Measurements at the Atmospheric Radiation Measurement Program Southern Site. In Proceedings of the Thirteenth Atmospheric Radiation Measurement Science Team Meeting, Albuquerque, NM, 2006.

Ramanathan, V. and Collins, W.: Thermodynamics regulation of ocean warming by cirrus clouds deduced from observations of the 1987 El-Niño, Nature, 351, 27-32, doi:10.1038/351027a0, 1991.
Ringer, M. A. and Allan, R. P.: Evaluating climate model simulations of tropical cloud, Tellus, 56A, 308-327, 2004.

Russel, P. B., Swissler, T. J., and McCormick, M. P.: Methodology for error analysis and simulation of lidar aerosol measurements, Appl. Opt., 22, 3783-3797, doi:10.1364/AO.18.003783, 1979.

Sassen, K.: Cirrus Clouds - A modern perspective, edited by: Lynch D. K., Sassen, K., Starr, D.O'C, and Stephens, G.: Cirrus, Oxford UniversityPress, London, 11-40, 2002.

Sassen, K. and Benson, S.: A mid-latitude cirrus cloud climatology from the facility for atmospheric remote sensing: Part II. Microphysical Properties Derived from Lidar Depolarization, Amer. Meteor. Soc., 58, 2103-2112, doi:10.1175/15200469(2001)0582.0.CO;2, 2001.

Sassen, K. and Campbell, J. R.: A mid-latitude cirrus cloud climatology from the facility for atmospheric remote sensing: Part I. Macrophysical and synoptic properties, Amer. Meteor. amt-2013-84Soc., 58, 481-496, doi:10.1175/15200469(2001)0582.0.CO;2, 2001.

Sassen, K. and Cho, B.: Thin Cirrus Lidar Dataset for Satellite Verification and Climatological Research, Amer. Meteor. Soc., 31, 1275-1285, 1992.

Sassen, K. and Comstock, J. M.: A Midlatitude Cirrus Cloud Climatology from the Facility for Atmospheric Remote Sensing. Part III: Radiative Properties, Amer. Meteor. Soc., 58, 2113 2127, doi:10.1175/1520-0469(2001)0582.0.CO;2, 2001.

Sassen, K., Griffin, M., and Dood, G. C.: Optical scattering and microphysical properties of subvisible cirrus clouds, and climatic implications, J. Appl. Meteorol., 28, 91-98, 1989.

Sassen, K., Zhu, J., and Benson, S.:Mid-latitude Cirrus Cloud Climatology from the Facility for Atmospheric Remote Sensing. IV Optical displays: Radiative Properties, Appl. Opt., 42, 332-341, doi:10.1364/AO.42.000332, 2003.

Sassen, K., Zhu, J. and Benson, S.: A Mid-latitude Cirrus Cloud Climatology from the Facility for Atmospheric Remote Sensing. Part V: Cloud Structural Properties, Amer. Meteor. Soc., 64, 2483-2501, doi:10.1175/JAS3949.1, 2007.

Sassen, K., Wang, Z. and Liu, D.: Global distribution of cirrus clouds from CloudSat/Cloud-Aerosol Lidar and Infrared Pathfinder Satellite Observations (CALIPSO) measurements, J. Geophys. Res., 113, D00A12, doi:10.1029/2008JD009972, 2008.

Seifert, P., Ansmann, A., Müller, D., Wandinger, U., Althausen, D., Heymsfield, A. J., Massie, S. T., and Schmitt, C.: Cirrus optical properties observed with lidar, radiosonde, and satellite over the tropical Indian ocean during the aerosol-polluted northeast and clean maritime southwest monsoon, J. Geophys. Res., 112, D17205, doi:10.1029/2006JD008352, 2007.

Takano, Y. and Liou, K. N.: Radiative transfer in cirrus clouds. III. Light scattering by irregular ice crystals, J. Atmos. Sci., 52, 818-837, doi:10.1175/15200469(1995)052<0818:RTICCP>2.0.CO;2, 1995.

Young, S. A.: Analysis of lidar backscatter profiles in optically thin clouds, Appl. Opt., 34, 7019-7031, doi:10.1364/AO.34.007019, 1995.

Wang, P. H., Minnis, P., McCormick, M. P., Kent, G. S., and Skeens, K. M.: A 6-year climatology of cloud occurrence frequency from Stratospheric Aerosol and Gas Experiment II observations (1985-1990), J. Geophys. Res., 101, 29407-29429, doi:10.1029/96JD01780, 1996. 
Whiteman, D. N., Demoz, B., and Wang, Z.: Subtropical cirrus cloud extinction to backscatter ratios measured by Raman Lidar during CAMEX-3, Geophys. Res. Lett., 31, 12105, doi:10.1029/2004GL020003, 2004.

Winker, D. M., Pelon, J., Coakley Jr., J. A., Ackerman, S. A., Charlson, R. J., Colarco, P. R., Flamant, P., Fu, Q., Hoff, R. M., Kittaka, C., Kubar, T. L., Treut, H. Le, McCormick, M. P., Mégie, G., Poole, L., Powell, K., Trepte, C., Vaughan, M. A., and Wielicki, B. A.: The CALIPSO mission: A global 3D view of aerosols and clouds, B. Am. Meteorol. Soc., 91, 1211-1229, doi:10.1175/2010BAMS3009.1, 2010. 